\title{
INTERVENÇÕES RECENTES E AVALIAÇÃO DE IMPACTES AMBIENTAIS NO BAIXO MONDEGO*
}

\author{
Lúcio Cunha**, A. F. Soares***, Alexandre Tavares***, A. Campar de Almeida** e José Gomes dos Santos**
}

\section{Resumo}

Um vasto conjunto de acções de desenvolvimento tem vindo a ser implementado no espaço do Baixo Mondego, na sequência das obras de regularização hidro-agrícola iniciadas nos anos 70 , com manifestos reflexos na economia local e nos modos de ordenar o território, mas também com alterações paisagísticas e impactes ambientais significativos. Para análise destes impactes utilizámos o método das matrizes de interacção, também conhecidas pela designação de matrizes de Leopold. Com a construção de três destas matrizes foi possível uma análise que se pretende holística e integrada das condições ambientais do Baixo Mondego, dos impactes sofridos e das principais ameaças a que está actualmente sujeito.

Da análise efectuada, ficou bem expresso o peso significativo que as transformações verificadas no Campo, e nomeadamente as modificações das técnicas agrícolas, estão a ter no desequilíbrio dos restantes ecossistemas do Baixo Mondego. Ressaltam, igualmente, os impactes fortemente negativos ligados à indústria extractiva, à indústria transformadora e à expansão urbana. Por outro lado, a agricultura, a pesca e mesmo actividades como o turismo têm um balanço menos negativo nos impactes que geram, representando importantes suportes do desenvolvimento económico e de defesa do património natural e cultural.

Palavras-chave: Estudos ambientais. Avaliação de impactes ambientais. Obras de regularização hidro-agrícola. Baixo Mondego. Portugal.

RÉSUMÉ

Un vaste ensemble d'actions de développement a été mis en oeuvre dans l'espace du Baixo Mondego, à la suite des travaux de régularization hydro-agricole initiés dans les années 70 , qui ont eu des reflets évidents dans l'économie locale et dans l'aménagement du territoire, aussi bien que dans l'altération du paysage avec des impacts significatifs dans l'environnement. Pour analyser ces impacts, nous avons utilisé la méthode des matrices d'interaction, qui sont aussi désignées par l'expression "matrices de Leopold". L'utilisation de trois de ces matrices nous a permis de faire une analyse holistique et intégrée des conditions environnementales du Baixo Mondego, des impacts subis et des principales menaces auxquelles il est soumis.

L'analyse accomplie nous montre bien l'influence que les transformations subies par le Campo, et notamment les modifications des techniques agricoles, ont eu au niveau du déséquilibre des autres écosystèmes du Baixo Mondego. Les impacts fort négatifs liés à l'industrie extractive, à l'industrie transformatrice et à l'expansion urbaine ont été également mis en relief. D'un autre côté, l'agriculture, la pêche et même des activités comme le tourisme ont un bilan moins négatif en ce qui concerne les impacts gérés. Ces activités constituent un support important dans le développement économique et la défense du patrimoine naturel et culturel.

Mots-clés: Études d'environnement. Évaluation d'impacts environnementales. Travaux de régularisation hydro-agricole. Baixo Mondego. Portugal.

* O presente artigo integra-se num conjunto diversificado de actividades de investigação desenvolvida por uma equipa interdisciplinar de geólogos e geógrafos da Universidade de Coimbra no âmbito de um projecto de investigação em financiamento pelo Programa PRAXIS XXI (2/21/CTA/156/94). Este projecto intitula-se "Estrutura geológica, evolução quaternária da paisagem e recursos no espaço do Baixo Mondego" e tem como objectivos estudar não só os processos geológicos e geomorfológicos envolvidos na evolução dos espaços e paisagens do Baixo Mondego durante o Quaternário, mas também proceder a um inventário dos recursos naturais então gerados e a uma avaliação dos impactes ambientais decorrentes das principais actividades humanas aqui desenvolvidas.

${ }^{* *}$ Instituto de Estudos Geográficos. Faculdade de Letras da Universidade de Coimbra.

*** Departamento de Ciências da Terra. Faculdade de Ciências e Tecnologia da Universidade de Coimbra. 


\section{Abstract}

Quite a lot of developing actions have been implemented in the area of the Baixo Mondego. These actions have been accomplished in the sequence of the hydro-agricultural works carried on in the beginning of 70's, which had a clear influence not only on the local economy and in the way of managing the territory, but in landscape and environmental impacts as well. In order to analyse these impacts, the matrices of interaction (also known as Leopold's matrices) method has been used. With the construction of three of these matrices, it was possible to examine the environmental conditions of the Baixo Mondego, as well as the impacts and the main threats it is subject to at present, using a holistic and integrated analysis.

From it it's possible to estimate the significant importance that the alterations in Campo - namely those in agricultural techniques - have been causing in the unbalance of the remaining ecological systems in the Baixo Mondego. The strong negative impacts are related to the extraction and transforming industries and urban growth. On the other hand, agriculture and fishing (and even activities such as tourism) show a less negative balance in the impacts they give rise to; they represent important foundations regarding economic development and the defence of natural and cultural patrimony.

Key words: Environmental studies. Assessment of environmental impacts. Hydro-agricultural regularisation works. Baixo Mondego. Portugal.

\section{INTRODUÇÃO}

O Baixo Mondego, entendido como a porção da bacia hidrográfica do Rio a jusante de Coimbra, ou seja aquela que se talha nos sedimentos da Orla Meso-Cenozóica Ocidental Portuguesa (SoARes, 1966; Almeida et al., 1990), é um espaço complexo, rico e polifacetado (que yai dos ásperos maciços calcários carsificados às suaves colinas gresosas e à verde planície litoral) cujo fio condutor, ou "fulcro", como lhe chamou há mais de cinquenta anos Alfredo Fernandes MARTINS (1940), está precisamente no troço inferior do Mondego ou Mondego Baixo (RIBEIRo, 1987) e na planície dos "Campos" que o bordeja. Do ponto de vista geomorfológico, esta é uma forma relativamente recente, progressivamente construída pelo Rio, através de cheias intermitentes e mais ou menos violentas, depois de terminado o avanço marinho ocorrido após o final do último período frio.

Um regime hidrológico de tipo semi-torrencial a par com algumas desajustadas intervenções processadas ao longo dos tempos históricos foram as causas principais de brutais cheias e extensas inundações nos campos do Mondego. Foi exactamente para domar estas e para minimizar os prejuízos sobre as culturas agrícolas e as vias de circulação, que se desenvolveu, há cerca de um quarto de século, um conjunto de obras de regularização hidro-agrícola que acabou por modificar significativamente a funcionalidade e fisionomia dos "Campos" e, de algum modo também, os modos de vida das populações do Baixo Mondego. Sobre este conjunto de intervenções e suas repercussões económicas e sociais há, neste momento, muitos trabalhos publicados ${ }^{1}$, destacando-se, a título de exemplo, o levantamento realizado, em 1988, por Pedro HESPANHA e José REIS onde pode ser encontrada uma sinopse histórica das intervenções realizadas, um elenco dos principais objectivos para elas traçados, algumas das razões que justificam os baixos níveis de participação das populações e o estudo dos impactes sociais e económicos da reconversão agrícola dos campos. Uma dezena de anos depois e apesar de, tanto quanto sabemos, ainda não estarem totalmente concluídas as obras previstas nos vários planos sectoriais de intervenção, nomeadamente no domínio da agricultura (rede de rega e emparcelamento, por exemplo), pensámos ser útil proceder a uma avaliação, ainda que sumária, dos impactes ambientais decorrentes das intervenções já realizadas e das transformações que acarretaram no funcionamento económico e social dos Campos do Mondego.

No entanto, esta análise não pode ser dissociada de um conjunto de acontecimentos e transformações mais gerais e de expressão espacial e temporal mais vasta. Com efeito, a nível nacional, estes últimos vinte anos foram palco de intensas transformações económicas e sociais, com repercussões imediatas ou mediatas, directas ou indirectas nos processos de organização do espaço e na qualidade do ambiente no Baixo Mondego. Muitas destas

\footnotetext{
1 Ver, por exemplo, o número 27 (Junho de 1998) da revista Sociedade e Território, integralmente dedicado ao Baixo Mondego.
} 
transformações decorreram, directa ou indirectamente, da integração portuguesa no espaço político e económico da União Europeia, como é o caso, por exemplo, da remodelação das estruturas viárias, da revitalização industrial, das transformações culturais agrícolas no "Campo" ou do abandono de muitas das culturas tradicionais de baixo rendimento no "Monte". Outras transformações decorrem apenas da tendência para a progressiva urbanização das populações, com aumento da dimensão dos centros urbanos da região, ou da tendência para o incremento das actividades turísticas, sobretudo as de "Sol e Mar" no litoral atlântico, e parecem enquadrar-se em movimentos económicos, sociológicos e geográficos de carácter mais geral e global.

Por estas razões, e porque nos pareceu extremamente difícil isolar as transformações apenas decorrentes das obras de regularização hidráulica e de re-estruturação do espaço agrícola, optámos por ensaiar uma análise dos diferentes impactes ambientais ocorridos no espaço do Baixo Mondego, por força de todo o conjunto de acções de desenvolvimento que aqui tiveram lugar neste último quarto de século. Para tal construímos um conjunto de três matrizes-síntese de impactes ambientais segundo o método das chamadas "matrizes de interacção" (LEOPOLD et al., 1971; MONTEIRO, 1988; FELIX-FILHO, 1994), as quais, apesar do carácter um tanto teórico e subjectivo de que se revestem, permitem com base no conhecimento que temos deste espaço e das várias actividades nele desenvolvidas, uma valoração, ou se preferirmos, uma avaliação semi-quantitativa dos respectivos impactes $^{2}$.

Pretendemos, assim, dar alguns passos no sentido da sistematização das alterações nas componentes ambientais aqui produzidas e, contribuir para a valorização e protecção dos seus recursos naturais (LAPA e MENDES, 1997; CRISTO, 1997), estimular o debate sobre a qualificação paisagística da área (ALMEIDA, 1997) e promover a discussão, sempre aberta, sobre as relações entre aç̧ões de promoção económica, social e cultural e o espaço físico envolvente (REBELO, CUNHA e ALMEIDA, 1990; PAIVA, 1996; CUNHA, 1997).

As acções de desenvolvimento levadas a cabo no espaço do Baixo Mondego, a partir da década de 70 , produziram nas componentes ambientais profundas alterações, tradutoras de impactes mais ou menos signi-

\footnotetext{
${ }^{2} \mathrm{Na}$ opinião de alguns autores (por exemplo, CONTRERAS, 1991) as matrizes de interacção, além de úteis na avaliação comparativa de diferentes alternativas para um mesmo projecto, servem sobretudo para avaliações gerais de projectos e é com esse propósito que aqui as utilizamos.
}

ficativos nos sistemas físicos, biológicos e sócio-económicos. A análise, que agora propomos, destes efeitos ou impactes, parte de um modelo de desenvolvimento sustentável, caracterizado por uma dimensão transgeracional que implica forçosamente uma integração do binómio ambiente-economia, uma adaptação do crescimento económico às capacidades biofísicas do meio, aos recursos naturais que este encerra e às variações sócio-culturais das sociedades. Este modelo baseia-se também numa adequação das políticas e avanços tecnológicos à gestão do ambiente e do território, visando reduzir os impactes e os custos ambientais inerentes.

Apesar da subjectividade de que se reveste, a avaliação proposta pretende ter um carácter valorativo de cariz semi-quantitativo, de acordo com o âmbito espacial e o alcance temporal dos impactes identificados. Assumimos, também, que o significado, extensão e alcance temporal de um determinado impacte ambiental dependem não só do efeito efectivamente verificado no ambiente em função do agente ou da actividade causadora mas, igualmente, da capacidade de leitura, do ponto de vista cultural e científico, que os autores têm sobre os aspectos ambientais em apreço, o seu valor e, mesmo, a sua capacidade de carga. Pretende-se, assim, contribuir para a adopção progressiva de critérios e de posições de algum modo pró-conservácionistas adaptadas a um modelo de ecodesenvolviment. ou, como já referimos, de desenvolvimento sustentável ac sua componente transgeracional.

\section{AS MATRIZES DE INTERACÇÃO - Considera- ções metodológicas}

Para a construção das matrizes de avaliação valorativa dos impactes ambientais registados no Baixo Mondego, o primeiro passo consistiu na selecção, tão alargada quanto possível, das acções de desenvolvimento postas em curso, as quais se repartem, ainda que com importância económica e social variável, por todos os sectores de actividade.

Feita esta inventariação, passou-se à identificação dos diferentes elementos e sub-elementos do ambiente susceptíveis de sofrerem efeitos ou impactes decorrentes do desenvolvimento destas actividades, tendo em atenção a especificidade do seu modo de funcionamento neste espaço.

A listagem das diferentes acções de desenvolvimento e dos elementos e sub-elementos ambientais considerados nesta análise, está expressa no Quadro I. 
Quadro I - Variáveis da matriz de impactes ambientais no Baixo Mondego

\begin{tabular}{|c|c|c|}
\hline \multirow{2}{*}{$\begin{array}{c}\text { Acções de } \\
\text { desenvolvimento }\end{array}$} & \multicolumn{2}{|r|}{ Impactes } \\
\hline & \begin{tabular}{|c|} 
Elemento do \\
Ambiente
\end{tabular} & $\begin{array}{c}\text { Sub-elemento do } \\
\text { Ambiente }\end{array}$ \\
\hline Agricultura e & \multirow{4}{*}{ Terra } & Morfologia continental \\
\hline exploração florestal & & Morfologia litoral \\
\hline \multirow{2}{*}{$\begin{array}{c}\text { Pesca e actividades } \\
\text { derivadas }\end{array}$} & & Solo \\
\hline & & Recursos minerais \\
\hline \multirow[t]{2}{*}{ Indústria extractiva } & \multirow{3}{*}{$\mathrm{Ar}$} & Qualidade do ar \\
\hline & & Ruído \\
\hline Indústria & & Clima \\
\hline transformadora & \multirow{3}{*}{ Água } & Mar \\
\hline \multirow[t]{2}{*}{ Urbanismo } & & Águas superficiais \\
\hline & & Águas subterrâneas \\
\hline \multirow[t]{2}{*}{ Turismo } & \multirow[t]{2}{*}{ Vida } & Flora \\
\hline & & Fauna \\
\hline $\begin{array}{l}\text { Construção de } \\
\text { Infra-estruturas }\end{array}$ & \multicolumn{2}{|l|}{ Paisagem } \\
\hline \multirow[t]{2}{*}{ Transportes } & \multirow{4}{*}{ Homem } & Aspectos sanitários \\
\hline & & "Risco" tecnológico \\
\hline \multirow[t]{2}{*}{ Outras actividades } & & $\begin{array}{c}\text { Aspectos económicos e } \\
\text { sociais }\end{array}$ \\
\hline & & $\begin{array}{l}\text { Aspectos culturais e } \\
\text { patrimoniais }\end{array}$ \\
\hline
\end{tabular}

Feita esta sistematização, estabeleceu-se uma metodologia de análise semi-quantitativa a partir da construção de três matrizes, de Sentido e Magnitude (Fig. 1), de Incidência Espacial (Fig. 2) e de Alcance Temporal (Fig. 3), em que se expressam os resultados da valoração atribuída a cada uma das relações causa-efeito que considerámos. Analisadas, quer individualmente, quer no seu conjunto, as matrizes permitiram valorar e hierarquizar as acções de desenvolvimento em função dos impactes ambientais que provocam, ou, se fizermos a leitura em sentido inverso, permitiram identificar para cada alteração ou distúrbio ambiental o agente ou agentes envolvidos a montante.

Como referimos já, não temos quaisquer dúvidas acerca do carácter fortemente subjectivo de que se revestem muitas das avaliações expressas nestas matrizes, apesar delas resultarem de um conhecimento aprofundado do modo como se desenvolvem as diferentes actividades económicas no espaço do Baixo Mondego e do funcionamento e capacidade de carga dos diferentes sub-sistemas ambientais. De facto, nem sempre foi possível aferir a percepção dos autores deste trabalho (CUNHA e JACINTO,
1995; DAVID e DUCRET, 1998) com os resultados de estudos técnicos já realizados ou mesmo com o sentimento geral da população que vive no Baixo Mondego manifestado, por exemplo, através de respostas a inquéritos especificamente elaborados com este fim ${ }^{3}$. E se muitas das relações que aqui se exprimem são praticamente pertença do chamado "senso comum", como, por exemplo, os impactes ambientais das pedreiras, tal como estão actualmente a ser exploradas, na qualidade da paisagem, ou as consequências dos incêndios florestais sobre as características da flora, da fauna ou mesmo sobre determinado tipo de processos geomorfológicos, outras relações serão, certamente, muito mais subtis ou mais complexas, por vezes com impactes múltiplos, variados e mesmo contraditórios no seu sentido.

Vejamos, muito rapidamente, alguns exemplos de relações de interacção actividade/elemento ambiental, ou seja de efeitos ou mesmo de impactes, cuja avaliação se reveste de um carácter de forte subjectividade:

- a valorização, que se entendeu positiva, dos recursos minerais pela indústria extractiva, decorrente do facto de apenas após a sua extracção estes recursos terem valor comercial. No entanto, se pensarmos que a extracção conduz à redução das reservas, podendo mesmo conduzir a um esgotamento mais ou menos rápido, poder-se-ia assumir uma posição de tipo contrário.

- a exploração florestal, feita em moldes modernos, tem impactes positivos ou negativos sobre a extensão do próprio espaço florestal, consoante se considerem as fases de plantação ou de abate das árvores.

- o campismo, ao aproveitar, em regra, espaços florestais pré-existentes tem sobre eles um duplo efeito: se, por um lado conduz ao abate de muitas árvores e à quase eliminação de todo o sub-bosque, por outro conduz ao ordenamento da floresta em que se integra, com redução do risco de incêndio e natural benefício, a prazo, para o espaço florestal. Em virtude deste carácter contraditório optámos por considerar "nulo" o impacte do campismo sobre o espaço florestal.

- situação semelhante é a que decorre da análise dos impactes da construção das barragens, do açude-ponte e mesmo da rede de rega sobre o conjunto da flora, cujos

3 Como, por exemplo, o inquérito realizado por MENDES e LiMA (1996). Com o objectivo de aferir a percepção das populações do "Campo" face às transformações verificadas neste espaço nos últimos anos, elaborámos e lançámos também um inquérito nas principais povoações do Baixo Mondego, cujos resultados foram já parcialmente apresentados no I Congresso sobre a Bacia do Mondego e serão objecto de uma nota a publicar brevemente. 


\begin{tabular}{|c|c|c|c|c|c|c|c|c|c|c|c|c|c|c|c|c|c|c|c|c|}
\hline & & & & Eellorare Expl. & Pescens & Indthatin & Indatrim & Urta- & Tortum. & & & Intmestronter & & & & Trmepport. & Ontrses & & & \\
\hline $\begin{array}{l}\text { ELEMENTO } \\
\text { DO } \\
\text { AMBIENTE }\end{array}$ & $\begin{array}{c}\text { SUB- } \\
\text { ELEMENTO }\end{array}$ & $\begin{array}{l}\text { EFErTO/ } \\
\text { /IMPACTE } \\
\text { EM: }\end{array}$ & 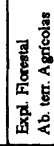 & 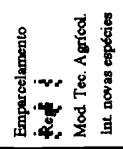 & 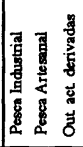 & & 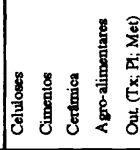 & 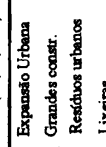 & 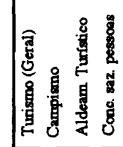 & 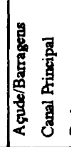 & 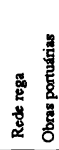 & $\begin{array}{ll}0 \\
0\end{array}$ & 送 & & & 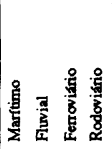 & 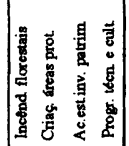 & Tabela qualitativa de & de valoraç̆o de $i$ & | Negentroes \\
\hline \multirow{7}{*}{ TERRA } & \multirow{5}{*}{$\begin{array}{l}\text { Morfologia } \\
\text { Continentalal }\end{array}$} & Vel. erososio & 9. & 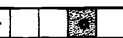 & & 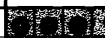 & & 19: & \begin{tabular}{l|l} 
& \\
\end{tabular} & +1 & +1 & (2) & 7 & & & & M+ & \multirow{3}{*}{ Fortes } & \multirow[b]{2}{*}{$+(+3)$} & \multirow[b]{2}{*}{ (-3) } \\
\hline & & Vet. sedimentaghso & 1 & 1 & & (3) & & 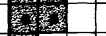 & 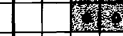 & ++ & + & 12 & 2 & & & & a. & & & \\
\hline & & Arreas de imundaçä & & & & & & 厚 & & ++1 & +4 & & & & & & & & \multirow{2}{*}{$+(+2)$} & \multirow{2}{*}{ (-2) } \\
\hline & & Estab. vert/alududes & 10 & & & as & & thol & & ++ & & olon & & 80 & & & (6). & \multirow[t]{2}{*}{ Modernderef } & & \\
\hline & & 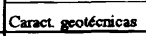 & 2 & & & 119 & & 4 & & $1+.+$ & & Hoto & 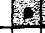 & 2 & 2 & & 19 & & \multirow{3}{*}{$+]_{(+1)}$} & \multirow{3}{*}{ 间 $(-1)$} \\
\hline & Moffologia & Deniva litoral & & & & & & & & 1 & $E$ & & 1 & 4 & & 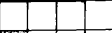 & I & \multirow[t]{2}{*}{ Fraceof } & & \\
\hline & Litoral & Bal. eros/sediment & & & & & & & & 3. & & & & & & 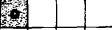 & 19 & & & \\
\hline
\end{tabular}


A

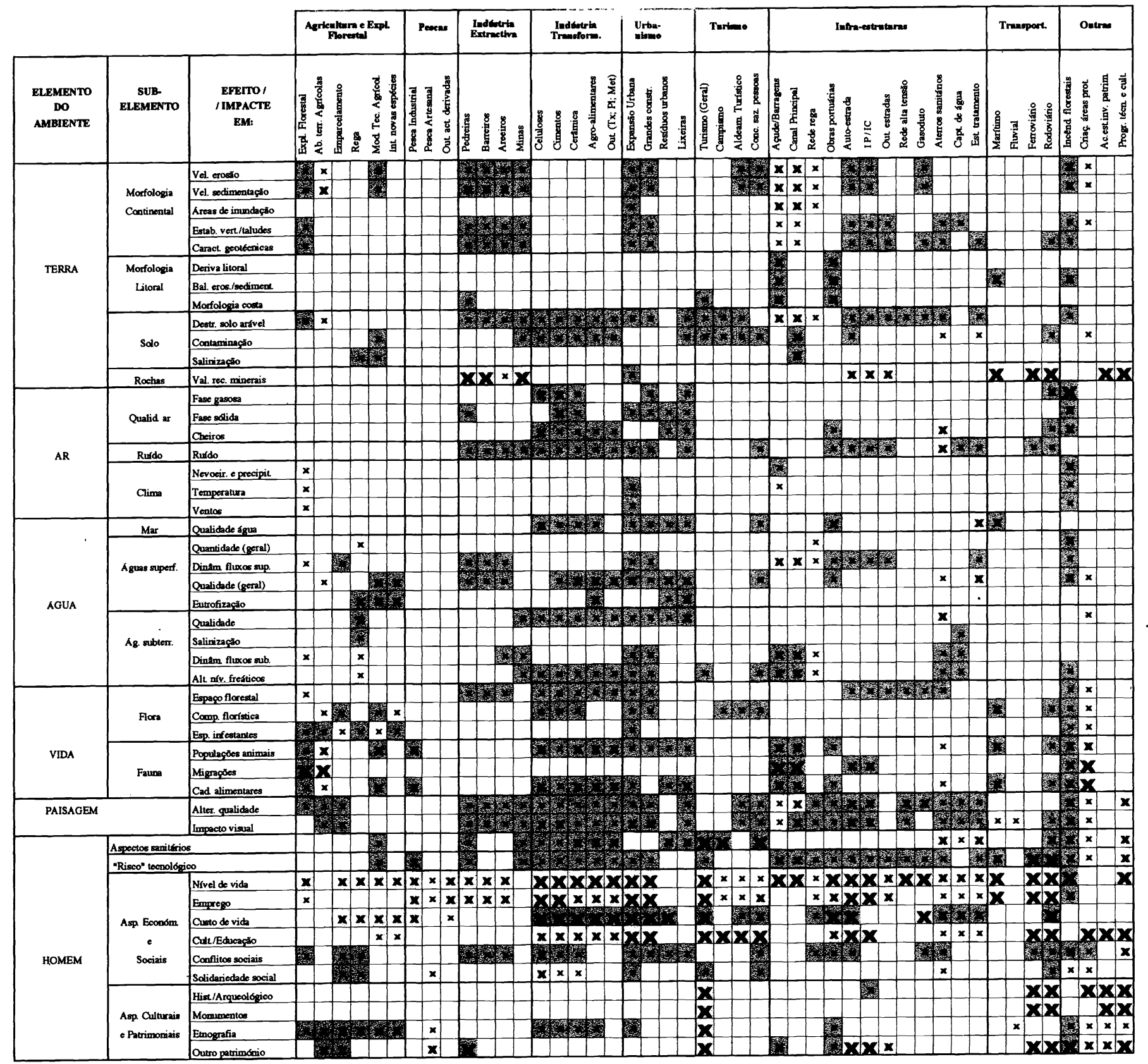

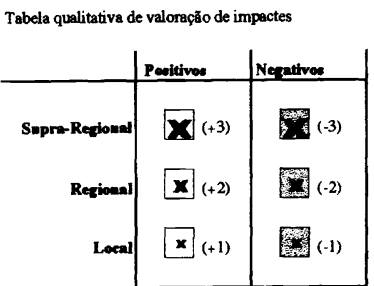




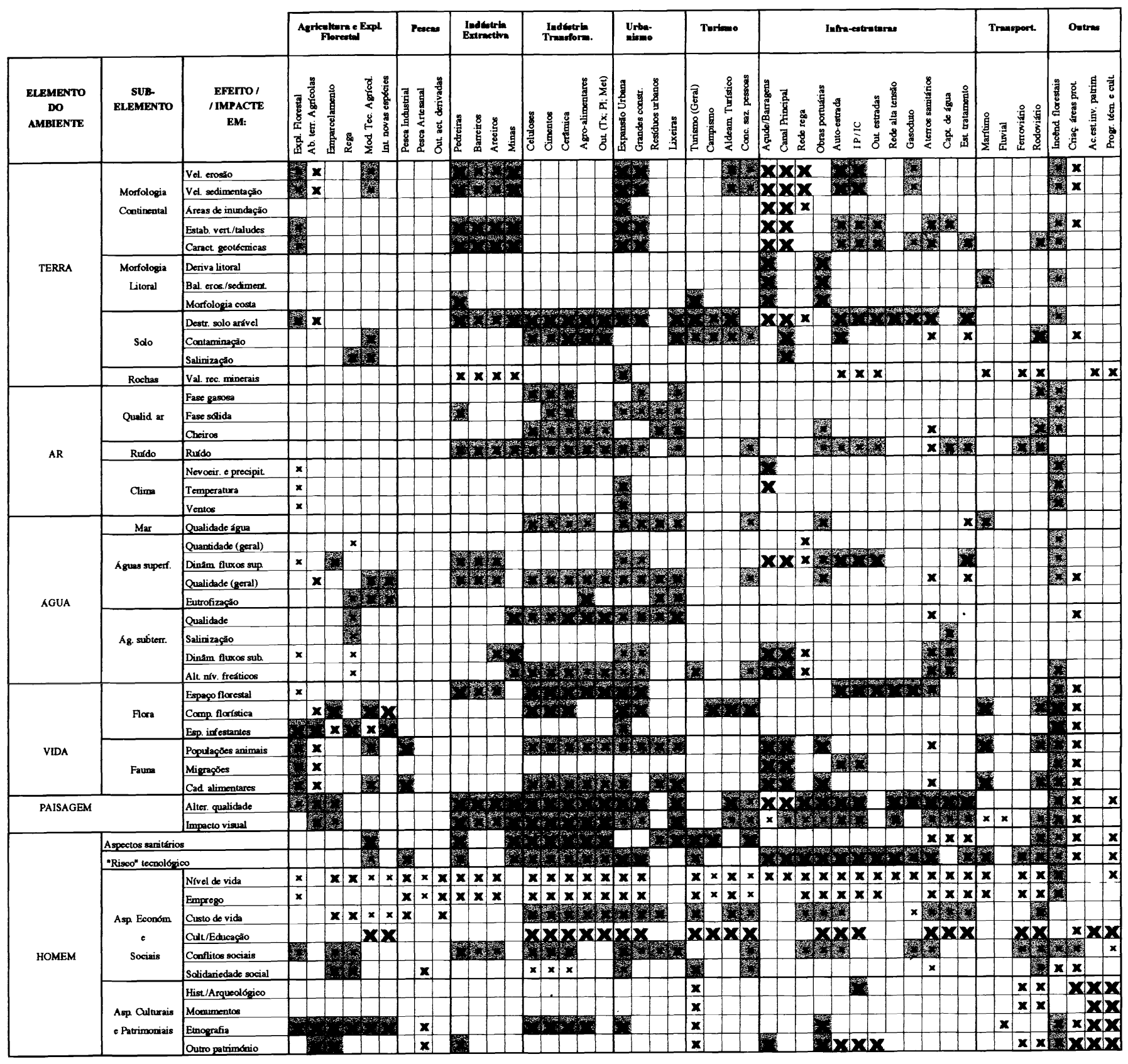

\begin{tabular}{|c|c|c|}
\hline & Poseltiver & INegetives \\
\hline Permaneaten & $\mathbf{x}^{(+3)}$ & $P(-3)$ \\
\hline Longo Praso & $x{ }_{(+2)}$ & 国筧 \\
\hline Tempertrio & $x_{(+1)}$ & 娄 \\
\hline
\end{tabular}


impactes foram considerados também "nulos" dado o carácter contraditório de que se revestem.

- a terminar este elenco meramente exemplificativo saliente-se a subjectividade generalizada na avaliação dos aspectos económicos, sociais e culturais, quanto ao sentido, mas também e sobretudo, quanto à sua incidência espacial e alcance temporal.

\section{ANÁLISE DAS MATRIZES}

Para a construção da Matriz de Sentido e Magnitude (Fig. 1), começámos por identificar o sentido do impacte (positivo ou negativo), a que se acrescentou a classificação respeitante à sua magnitude, surgindo assim, três graus qualitativos (fracos, moderados e fortes). A ausência de valoração traduz, quer a ausência de impactes, quer o equilíbrio de sentido do conjunto dos mesmos.

A cada uma das seis classes resultantes foi atribuída uma valoração (ver legenda da Fig. 1) cujo somatório permitirá hierarquizar as acções de desenvolvimento enquanto geradoras de impactes ambientais, potenciais ou efectivos, ou os elementos ambientais mais afectados.

Nos Quadros II e III aparecem sintetizados os valores encontrados para os somatórios da Matriz de Sentido e Magnitude, assim como a respectiva representatividade, a fim de permitir uma qualificação das acções de desenvolvimento.

Quadro II - Qualificação dos impactes ambientais decorrentes das acções de desenvolvimento de acordo com a Matriz de Sentido e Magnitude

\begin{tabular}{|l|c|c|c|}
\hline \multicolumn{1}{|c|}{ Descrição } & Intervalo & $\begin{array}{c}\mathrm{N}^{\circ} \text { de } \\
\text { acções }\end{array}$ & $\begin{array}{c}\text { Representa- } \\
\text { tividade (\%) }\end{array}$ \\
\hline Impactes muito positivos & $>(+15)$ & 2 & 4,4 \\
\hline Impactes positivos & ]$+5,+15]$ & 4 & 8,7 \\
\hline Impactes reduzidos & $\mathbf{] - 5 , + 5 ]}$ & $\mathbf{1 6}$ & $\mathbf{3 4 , 8}$ \\
\hline Impactes negativos & $\mathbf{] - 1 5 , - 5 ]}$ & 8 & 17,4 \\
\hline Impactes muito negativos & $\mathrm{]}-25,-15]$ & 9 & 19,6 \\
\hline $\begin{array}{l}\text { Impactes extremamente } \\
\text { negativos }\end{array}$ & $\leq(-25)$ & 7 & 15,2 \\
\hline
\end{tabular}

A análise da representatividade das classes permite afirmar que há uma preponderância das situações geradoras de impactes negativos no seu conjunto, a que se seguem as acções com impactes reduzidos.
No Quadro III identificam-se as acções geradoras dos impactes ambientais mais positivos e mais negativos, apontando-se o valor do somatório encontrado para cada um deles.

Quadro III - Acções geradoras dos impactes mais positivos e mais negativos

\begin{tabular}{|c|c|c|c|}
\hline $\begin{array}{c}\text { Acções geradoras dos } \\
\text { impactes mais positivos }\end{array}$ & $\Sigma$ & $\begin{array}{c}\text { Acções geradoras } \\
\text { dos impactes mais } \\
\text { negativos }\end{array}$ & $\Sigma$ \\
\hline Criação de áreas protegidas & $(+29)$ & Incêndios florestais & $(-55)$ \\
\hline Progresso cultural e técnico & $(+17)$ & Lixeiras & $(-41)$ \\
\hline $\begin{array}{c}\text { Acções estrut. invent. } \\
\text { património }\end{array}$ & $(+12)$ & Expansão urbana & $(-41)$ \\
\hline Turismo (Geral) & $(+12)$ & Pedreiras & $(-31)$ \\
\hline Pesca artesanal & $(+9)$ & $\begin{array}{c}\text { Indústria de } \\
\text { Celulose }\end{array}$ & $(-28)$ \\
\hline
\end{tabular}

A observação da Matriz de Sentido e Magnitude de Impactes, bem como dos respectivos somatórios para cada uma das acções de desenvolvimento, permite tirar as seguintes ilações:

- as acções de desenvolvimento, que no seu conjunto, são responsáveis por impactes de sentido negativo de maior magnitude resultam das actividades ligadas à indústria, extractiva e transformadora, e à urbanização; apesar de não poderem considerar-se acções de desenvolvimento, mas antes uma das suas consequências, destacam-se, também, os incêndios florestais por apresentarem impactes ambientais extremamente negativos, nomeadamente os respeitantes à alteração dos elementos físicos;

- a construção de infra-estruturas gera, no espaço do Baixo Mondego, impactes com sentido e magnitude muito diversos;

- as actividades agrícolas, o turismo e os transportes, apresentam no seu conjunto impactes de baixa magnitude;

- as acções resultantes das alterações agrícolas e hídricas, implementadas nas últimas três décadas no Baixo Mondego, parecem ter produzido, por si só, impactes ambientais de significado reduzido;

- com reflexos positivos apresentam-se as actividades de preservação e conservação ambiental e as que se ligam ao progresso científico e tecnológico.

Analisando, agora, os impactes sobre os diferentes elementos ambientais, a observação desta matriz permite ainda assinalar:

- os impactes fortemente negativos na morfologia continental, na fauna e na flora impostos pelos incêndios florestais;

- os impactes negativos na morfologia continental provocados pela indústria extractiva; 
- o impacte negativo no ar (qualidade e ruído) e na qualidade da água resultantes da indústria transformadora e do urbanismo;

- os fortes impactes na paisagem produzidos pelas indústrias extractiva e transformadora e pelo urbanismo;

- o risco tecnológico não dispiciendo que se associa a actividades da indústria transformadora;

- os impactes diversos produzidos na água e vida em resultado das actividades agrícolas e florestais;

- os impactes genericamente positivos decorrentes do conjunto das obras hidráulicas na morfologia continental;

- destaca-se ainda o impacte fortemente positivo sobre o Homem, devido principalmente a uma significativa valorização económica, através de diversos parâmetros como o nível de vida e o emprego, resultantes da indústria transformadora, urbanismo, turismo e da construção de infra-estruturas.

Para avaliar a incidência espacial dos impactes decorrentes das acções de desenvolvimento elaborou-se uma segunda matriz, designada por Matriz de Incidência Espacial (Fig. 2). Assim, e para os dois sentidos (positivo e negativo) anteriormente definidos avaliaram-se os impactes como tendo incidência local, regional (conjunto do Baixo Mondego) ou supra-regional.

Uma primeira leitura desta matriz permite observar, por um lado, o domínio dos impactes com incidência local, e, por outro, a concentração do carácter supra-regional associado ao elemento Homem.

O somatório dos impactes para cada acção de desenvolvimento e a projecção destes nos vários intervalos de qualificação e respectiva representatividade aparecem expressos no Quadro IV.

Destaca-se o reduzido número de acções que produziram impactes nitidamente positivos (13\%) e o predomínio das que se traduziram por impactes reduzidos $(43,4 \%)$.

Quadro IV - Qualificação dos impactes ambientais segundo as acções de desenvolvimento de acordo com a Matriz de Incidência Espacial

\begin{tabular}{|l|c|c|c|}
\hline \multicolumn{1}{|c|}{ Descrição } & $\begin{array}{c}\text { Intervalo } \\
\Sigma\end{array}$ & $\begin{array}{c}\mathrm{N}^{\circ} \text { de } \\
\text { acções }\end{array}$ & $\begin{array}{c}\text { Representa- } \\
\text { tividade (\%) }\end{array}$ \\
\hline Impactes muito positivos & $>(+15)$ & 3 & 6,5 \\
\hline Impactes positivos & ]$+5,+15]$ & 3 & 6,5 \\
\hline Impactes reduzidos & $\mathbf{] - 5 , + 5 ]}$ & $\mathbf{2 0}$ & $\mathbf{4 3 , 4}$ \\
\hline Impactes negativos & $\mathbf{] - 1 5 , - 5 ]}$ & 9 & 19,6 \\
\hline Impactes muito negativos & $\mathbf{] - 2 5 , - 1 5 ]}$ & 9 & 19,6 \\
\hline $\begin{array}{l}\text { Impactes extremamente } \\
\text { negativos }\end{array}$ & $\leq(-25)$ & 2 & 4,4 \\
\hline
\end{tabular}

Os resultados extremos dos valores-somatório obtidos na Matriz de Incidência Espacial estão resumidos no Quadro V.

Quadro V - Acçōes geradoras dos impactes com maior ou menor incidência espacial

\begin{tabular}{|c|c|c|c|}
\hline $\begin{array}{c}\text { Acções geradoras dos } \\
\text { impactes mais positivos }\end{array}$ & $\Sigma$ & $\begin{array}{c}\text { Acções geradoras } \\
\text { dos impactes mais } \\
\text { negativos }\end{array}$ & $\Sigma$ \\
\hline Criação de áreas protegidas & $(+30)$ & Incêndios florestais & $(-53)$ \\
\hline Progresso cultural e técnico & $(+27)$ & Expansão urbana & $(-24)$ \\
\hline Transporte ferroviário & $(+16)$ & Lixeiras & $(-21)$ \\
\hline $\begin{array}{c}\text { Acções estrut. invent. } \\
\text { património }\end{array}$ & $(+15)$ & $\begin{array}{c}\text { Indústria cerâmica } \\
(-19)\end{array}$ \\
\hline $\begin{array}{c}\text { Turismo (geral) } \\
(+9)\end{array}$ & $\begin{array}{c}\text { Indústria de } \\
\text { celulose }\end{array}$ & $(-18)$ \\
\hline
\end{tabular}

A análise dos resultados permite as seguintes considerações:

- à semelhança do que já acontecia com a matriz anteriormente analisada, os incêndios florestais registam valores extremamente negativos, de âmbito frequentemente regional;

- a indústria transformadora e o urbanismo apresentam, no seu conjunto, impactes muito negativos, ainda que de incidência essencialmente local ou regional;

- as actividades de preservação e conservação ambiental e as que se associam ao progresso científico e técnico das sociedades são as que apresentam resultados mais positivos e com reflexos que ultrapassam o espaço físico do Baixo Mondego;

- o transporte ferroviário destaca-se pelo impacte positivo, com significado supra-regional, relativamente às outras formas alternativas de transporte da região;

- as alterações hidráulicas produzidas no Baixo Mondego nas últimas décadas têm naturalmente impactes de carácter essencialmente regional, embora com sentidos diversos em função do elemento ambiental em análise;

- salienta-se, também, a deterioração, a nível regional, da qualidade da água superficial devido à indústria transformadora, urbanismo e modificações agrícolas;

- destaca-se, ainda, o carácter nitidamente supra-regional (que em alguns casos poderá assumir um significado de carácter nacional) dos aspectos económicos resultantes da indústria transformadora, urbanismo, infra-estruturas e transportes, a valorização dos recursos minerais pela indústria extractiva e pelos transportes, a valorização económica, cultural e patrimonial por parte do turismo, 
em geral, e a valorização dos aspectos culturais e patrimoniais, função dos transportes ferroviários e rodoviários e das actividades de progresso e inventariação científica e cultural.

Procurando, finalmente, a avaliação do carácter temporal dos impactes construiu-se uma terceira matriz designada por Matriz de Alcance Temporal (Fig. 3). Assim, tendo por base o sentido positivo ou negativo, identificaram-se os impactes como temporários (nalgumas situações como sinónimo de episódico), de longo prazo e permanentes. A distinção entre temporário e de longo prazo resulta, para este último, da produção de impactes num período superior a 10 anos; o carácter permanente caracteriza acções igualmente superiores a 10 anos, mas irreversíveis, com manutenção do efeito mesmo após a cessação da acção.

Uma primeira e breve análise desta matriz permite visualizar a menor importância dos impactes de carácter temporário e a elevada representatividade dos que assumem um carácter permanente, em regra associados a impactes de sentido negativo.

Igualmente, para cada uma das seis classes consideradas foi atribuída uma valoração, cujos somatórios permitem qualificar as acções de desenvolvimento de acordo com o carácter temporal de incidência do impacte.

No Quadro VI aparecem representados os intervalos de projecção dos valores-somatório da Matriz de Alcance Temporal e a respectiva representatividade.

Quadro VI - Qualificação dos impactes ambientais segundo as acções de desenvolvimento de acordo com a Matriz de Alcance Temporal

\begin{tabular}{|l|c|c|c|}
\hline \multicolumn{1}{|c|}{ Descrição } & $\begin{array}{c}\text { Intervalo } \\
\Sigma\end{array}$ & $\begin{array}{c}\mathrm{N}^{\text {o }} \text { de } \\
\text { acções }\end{array}$ & $\begin{array}{c}\text { Representati- } \\
\text { vidade (\%) }\end{array}$ \\
\hline Impactes muito positivos & $>(+15)$ & 3 & 6,5 \\
\hline Impactes positivos & ]$+5,+15]$ & 4 & 8,7 \\
\hline Impactes reduzidos & ]$-5,+5]$ & 10 & 21,7 \\
\hline Impactes negativos & ]$-15,-5]$ & 11 & 23,9 \\
\hline Impactes muito negativos & ]$-25,-15]$ & 6 & 13,0 \\
\hline $\begin{array}{l}\text { Impactes extremamente } \\
\text { negativos }\end{array}$ & $\leq \mathbf{- 2 5})$ & $\mathbf{1 2}$ & $\mathbf{2 6 , 1}$ \\
\hline
\end{tabular}

A análise da representatividade das classes permite afirmar que há uma preponderância das situações geradoras de impactes negativos e um incremento da classe de impactes extremamente negativos, relativamente às matrizes anteriores.
No Quadro VII aparecem identificadas as acções geradoras dos impactes ambientais mais positivos e mais negativos, de acordo com a sua valoração temporal, apontando-se o valor do somatório encontrado nesta matriz.

Quadro VII - Acções geradoras dos impactes de maior ou menor alcance temporal

\begin{tabular}{|c|c|c|c|}
\hline $\begin{array}{c}\text { Acções geradoras dos } \\
\text { impactes mais } \\
\text { positivos }\end{array}$ & $\Sigma$ & $\begin{array}{c}\text { Acções geradoras } \\
\text { dos impactes mais } \\
\text { negativos }\end{array}$ & $\Sigma$ \\
\hline $\begin{array}{c}\text { Criação de áreas } \\
\text { protegidas }\end{array}$ & $(+43)$ & Expansão urbana & $(-56)$ \\
\hline $\begin{array}{c}\text { Progresso cultural e } \\
\text { técnico }\end{array}$ & $(+26)$ & Incêndios florestais & $(-50)$ \\
\hline $\begin{array}{c}\text { Acções estrut. invent. } \\
\text { património }\end{array}$ & $(+17)$ & Lixeiras & $(-42)$ \\
\hline Rede de Rega & $(+13)$ & Indústria Cerâmica & $(-40)$ \\
\hline Transporte Ferroviário & $(+12)$ & Indústria de Cimentos & $(-39)$ \\
\hline
\end{tabular}

A observação dos valores somatório da Matriz de Alcance Temporal de Impactes permite as seguintes considerações:

- o conjunto da indústria extractiva e transformadora bem como o urbanismo são caracterizados por impactes ambientais muito negativos e/ou extremamente negativos;

- a criação de infra-estruturas como as obras portuárias, a auto-estrada e os itinerários principais e complementares traduziu-se igualmente por impactes muito negativos a extremamente negativos;

- confirma-se a valoração muito positiva para as acções ligadas às actividades de preservação e conservação ambiental e de progresso científico e técnico.

Com base nesta matriz mas numa outra perspectiva de análise, o diferenciado grau de susceptibilidade dos elementos do ambiente, possibilita as seguintes observações:

- a morfologia continental é afectada de forma permanente pelas acções relacionadas com a indústria extractiva, pela expansão e construção urbana e, ainda, pela construção de infra-estruturas;

- a destruição de solo arável, por vezes com contaminação, constitui-se como um dos impactes com carácter permanente decorrente de diversas acções de desenvolvimento;

- as alterações permanentes na flora resultam da acção da indústria transformadora, do urbanismo, da criação de algumas infra-estruturas e dos incêndios florestais; 
- a paisagem é afectada de forma negativa e permanente em consequência da acção das indústrias extractiva e transformadora, pelo urbanismo e pela construção de infra-estruturas;

- o risco tecnológico permanente encontra-se associado à construção e expansão urbanas e à criação de infra-estruturas;

- os impactes sanitários negativos estão fundamentalmente associados à indústria transformadora e ao turismo;

- a flora e a fauna reflectem impactes com sentido e grau de reversibilidade diversos decorrentes da actividade agrícola e de exploração florestal;

- de realçar a valorização dos aspectos culturais e patrimoniais, bem como o seu carácter permanente, associados às actividades estruturantes e de inventário do património, de progresso científico e técnico e de criação de áreas protegidas;

- de assinalar, finalmente, a significativa desvalorização que os aspectos etnográficos sofrem por acção das transformações agrícolas, da exploração florestal e da indústria transformadora mas, e como contraponto, a valorização que as actividades de estudo e inventariação do património e o progresso tecnológico e científico exercem sobre estes mesmos elementos do ambiente.

Após a análise de cada uma das matrizes, importa agora caracterizar as acções de desenvolvimento no seu todo, a partir do somatório final das três matrizes. No Quadro VIII aparecem expressos os intervalos finais de qualificação dos impactes para aplicação ao somatório das matrizes de Sentido e Magnitude, de Incidência Espacial e de Alcance Temporal.

$\mathrm{O}$ número de acções de desenvolvimento que cai em cada intervalo evidencia, por um lado, o domínio de acções com impactes negativos, a importante representatividade das acções com impactes ambientais extremamente negativos, e por outro, o limitado número de acções com impactes positivos.

Quadro VIII - Qualificação final das acções de desenvolvimento a partir do somatório das três matrizes

\begin{tabular}{|l|c|c|c|}
\hline \multicolumn{1}{|c|}{ Descrição } & $\begin{array}{c}\text { Intervalo } \\
\Sigma\end{array}$ & $\begin{array}{c}\mathrm{N}^{\circ} \text { de } \\
\text { acções }\end{array}$ & $\begin{array}{c}\text { Representa- } \\
\text { tividade (\%) }\end{array}$ \\
\hline Impactes muito positivos & $>(+45)$ & 2 & 4,4 \\
\hline Impactes positivos & ]$+15,+45]$ & 6 & 13,0 \\
\hline Impactes reduzidos & $\mathbf{] - 1 5 , + 1 5 ]}$ & $\mathbf{1 3}$ & $\mathbf{2 8 , 3}$ \\
\hline Impactes negativos & ]$-45,-15]$ & 10 & 21,7 \\
\hline Impactes muito negativos & ]$-75,-45]$ & 6 & 13,0 \\
\hline $\begin{array}{l}\text { Impactes extremamente } \\
\text { negativos }\end{array}$ & $<(-75)$ & 9 & 19,6 \\
\hline
\end{tabular}

Nos Quadros IX e X e na Fig. 4, assinalam-se as acções de desenvolvimento no Baixo Mondego que, isoladamente (Quadro IX) ou em grupo (Quadro X e Fig. 4) registaram impactes ambientais com valoração extrema, positiva ou negativa.

\section{Quadro IX - Acções geradoras de impactes com maior valoração (magnitude, incidência espacial e alcance temporal)}

\begin{tabular}{|c|c|c|c|}
\hline $\begin{array}{c}\text { Acções geradoras dos } \\
\text { impactes mais positivos }\end{array}$ & $\Sigma$ & $\begin{array}{c}\text { Acções geradoras } \\
\text { dos impactes } \\
\text { mais negativos }\end{array}$ & $\Sigma$ \\
\hline $\begin{array}{c}\text { Criação de áreas } \\
\text { protegidas }\end{array}$ & $(+102)$ & $\begin{array}{c}\text { Incêndios } \\
\text { florestais }\end{array}$ & $(-157)$ \\
\hline $\begin{array}{c}\text { Progresso cultural e } \\
\text { técnico }\end{array}$ & $(+70)$ & Expansão urbana & $(-121)$ \\
\hline $\begin{array}{c}\text { Acções estrut. invent. } \\
\text { património }\end{array}$ & $(+44)$ & Lixeiras & $(-104)$ \\
\hline Transporte ferroviário & $(+33)$ & Indústria cerâmica & $(-85)$ \\
\hline $\begin{array}{c}\text { Rede de rega } \\
\text { Eesca artesanal } \\
\text { celulose }\end{array}$ & $(+25)$ & $\begin{array}{c}\text { Indústria da } \\
\text { cimentos }\end{array}$ & $(-83)$ \\
\hline $\begin{array}{c}\text { Purismo (geral) } \\
\text { Putria de }\end{array}$ & $(+17)$ & Pedreiras & $(-82)$ \\
\hline $\begin{array}{c}\text { Outras actividades } \\
\text { derivadas da pesca }\end{array}$ & $(+16)$ & $\begin{array}{c}\text { Indústria agro- } \\
\text { alimentar }\end{array}$ & $(-81)$ \\
\hline $\begin{array}{c}\text { Abandono terrenos } \\
\text { agrícolas, Canal } \\
\text { principal, Transporte } \\
\text { fluvial }\end{array}$ & $(+7)$ & $\begin{array}{c}\text { Grandes } \\
\text { construções }\end{array}$ & $(-80)$ \\
\hline
\end{tabular}

A criação de áreas protegidas, o progresso tecnológico e cultural e as actividades de estudo e inventariação do património assumem-se como as intervenções antrópicas recentes no Baixo Mondego que geraram impactes mais positivos, visíveis, por exemplo, a nível da fauna, flora e paisagem ou, ainda, dos diversos aspectos afectos ao elemento "Homem".

No extremo oposto, os incêndios florestais e alguns factores relacionados com o urbanismo, designadamente a expansão urbana e as lixeiras, estão na base das intervenções que produziram impactes mais negativos. A sua acção pode ler-se, directa ou indirectamente nos efeitos que provocaram na morfologia continental, na qualidade do ar e da água do mar, no solo arável ou, ainda, nos desequilíbrios causados nos sistemas hidrológicos (superficial e subterrâneo), na fauna e flora e, finalmente, na degradação da qualidade da paisagem, elemento onde acabam por reflectir-se, de forma indelével, os efeitos 
exercidos sobre os elementos anteriores. Destaque-se, ainda, a forte correlação entre aquelas três categorias de intervenções antrópicas o incremento do risco tecnológico e a deterioração dos aspectos sanitários.

A análise do Quadro X e da Fig. 4 permite uma ideia geral da maior ou menor importância dos impactes gerados por cada grupo de actividades, destacando-se, para já, as seguintes conclusões:

- o somatório muito negativo do conjunto de impactes associado à indústria transformadora e ae urbanismo;

- a obtenção de valores baixos, positivos, e apenas associados às actividades de pesca, de transporte e ao grupo heterogéneo genericamente designado por "outras" (apesar de se incluirem aqui os valores fortemente negativos dos incêndios florestais);

- os valores negativos associados às actividades agrícolas e exploração florestal, à indústria transformadora e à criação de infra-estruturas aparecem penalizados pelo alcance temporal dos impactes, com manifestações a longo prazo ou permanentes;

- os impactes negativos associados à indústria extractiva aparecem minimizados pelo carácter local da incidência espacial;

- os impactes ambientais associados ao urbanismo apresentam os valores menos negativos na incidência espacial, dominantemente local;

- a valoração positiva dos impactes associados aos transportes é dominantemente suportada pela incidência espacial.

Se procurarmos efectuar uma leitura cruzada dos resultados das três matrizes, facilmente se concluirá, ainda, que:

- os impactes positivos têm uma incidência espacial com contornos regionais ou mesmo supra-regionais, em contraponto com os impactes negativos cujos efeitos produzidos são basicamente de âmbito local;

- os impactes sobre os elementos físicos do ambiente são essencialmente de âmbito local, o mesmo não acontecendo com os impactes sobre o Homem, de âmbito regional ou mesmo supra-regional.

- os impactes positivos têm, de um modo geral, um longo alcance temporal dado o carácter de longo prazo dos efeitos que produzem sobre os elementos do ambiente; já os impactes negativos, em termos de alcance temporal caracterizam-se pelo forte carácter permanente dos seus efeitos, que persistem mesmo que cesse a acção que os gerou, o que se traduz pela irreversibilidade das consequências que produzem sobre os elementos do ambiente.
Quadro X - Grupos de acções geradoras de impactes
com maior valoração
(magnitude, incidência espacial e alcance temporal)

\begin{tabular}{|c|c|c|c|c|}
\hline $\begin{array}{c}\text { Conjunto de } \\
\text { acções }\end{array}$ & $\begin{array}{c}\Sigma \text { Matriz de } \\
\text { Sentido e } \\
\text { Magnitude }\end{array}$ & $\begin{array}{c}\Sigma \text { Matriz de } \\
\text { Incidência } \\
\text { Espacial }\end{array}$ & $\begin{array}{c}\Sigma \text { Matriz } \\
\text { de } \\
\text { Alcance } \\
\text { Temporal }\end{array}$ & $\Sigma$ Final \\
\hline $\begin{array}{c}\text { Agr. e Expl. } \\
\text { Flor. }\end{array}$ & -28 & -22 & -50 & -100 \\
\hline Pesca & $\mathbf{+ 1 6}$ & +11 & +12 & +39 \\
\hline Ind. Extractiva & -87 & -39 & -114 & -240 \\
\hline Ind. Transf. & $\mathbf{- 1 1 4}$ & $\mathbf{- 9 1}$ & $\mathbf{- 1 7 8}$ & $\mathbf{- 3 8 3}$ \\
\hline Urbanismo & -129 & -76 & -152 & -361 \\
\hline Turismo & -3 & -6 & -29 & -38 \\
\hline Infra-estruturas & -44 & -30 & -103 & -177 \\
\hline Transportes & +3 & +17 & +2 & +22 \\
\hline Outras & +5 & $\mathbf{+ 2 0}$ & $\mathbf{+ 3 6}$ & $\mathbf{+ 6 1}$ \\
\hline & & & &
\end{tabular}

$\Sigma$

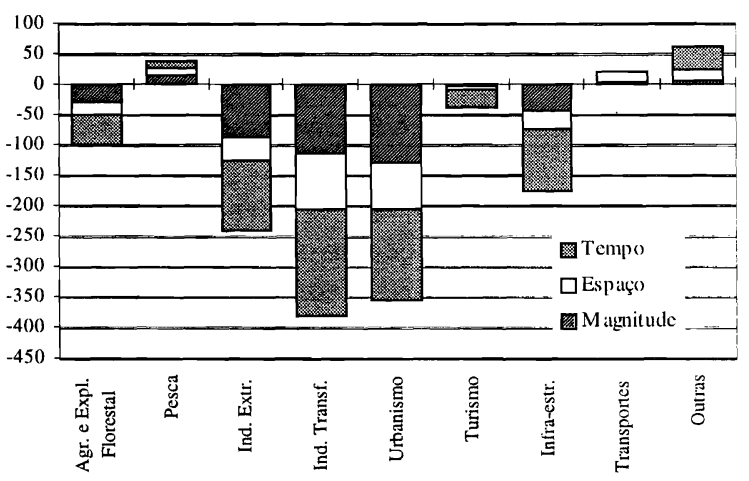

Fig. 4 - Valoração total dos impactes ambientais por grupos de acções de desenvolvimento

No Quadro XI e na Fig. 5 é possível observar, para os vários elementos do ambiente, a valoração dos efeitos decorrentes do conjunto das acções de desenvolvimento efectuadas no Baixo Mondego. Os resultados obtidos, com base nos valores parciais e finais das matrizes permitem concluir que:

- somente para o elemento "Homem" os impactes resultaram positivos; esta valoração positiva resulta essencialmente da incidência espacial, neste caso regional ou supra-regional dos impactes das acções de desenvolvimento ensaiadas no Baixo Mondego;

- os elementos "Terra", "Água" e "Vida" são particularmente penalizados por impactes com alcance temporal permanente, com carácter irreversível; no entanto, os 
primeiros são minimizados por uma incidência espacial de âmbito essencialmente local;

- o mesmo se pode concluir para os impactes sobre a paisagem. De salientar que este elemento ambiental, apesar de avaliado por apenas duas das suas características (alteração da qualidade e impacte visual), regista valores negativos da mesma ordem de grandeza que os registados noutros elementos, o que testemunha, de forma inequívoca, a profunda e algo desequilibrada intervenção do Homem sobre este espaço.

Quadro XI - Valoração dos impactes sobre os diferentes elementos ambientais

\begin{tabular}{|c|c|c|c|c|}
\hline $\begin{array}{c}\text { Elemento } \\
\text { do } \\
\text { ambiente }\end{array}$ & $\begin{array}{c}\Sigma \text { Matriz de } \\
\text { Sentido e } \\
\text { Magnitude }\end{array}$ & $\begin{array}{c}\Sigma \text { Matriz de } \\
\text { Incidência } \\
\text { Espacial }\end{array}$ & $\begin{array}{c}\Sigma \text { Matriz de } \\
\text { Alcance } \\
\text { Temporal }\end{array}$ & $\Sigma$ Final \\
\hline Terra & $\mathbf{- 1 1 5}$ & -62 & -169 & $\mathbf{- 3 4 6}$ \\
\hline Ar & -79 & -51 & -74 & -204 \\
\hline Água & -95 & $\mathbf{- 8 5}$ & -130 & -310 \\
\hline Vida & -85 & -83 & $\mathbf{- 1 7 1}$ & -339 \\
\hline Paisagem & -92 & -57 & -108 & -257 \\
\hline Homem & $\mathbf{+ 5 3}$ & $\mathbf{+ 1 2 1}$ & $\mathbf{+ 7 0}$ & $\mathbf{+ 2 4 4}$ \\
\hline
\end{tabular}

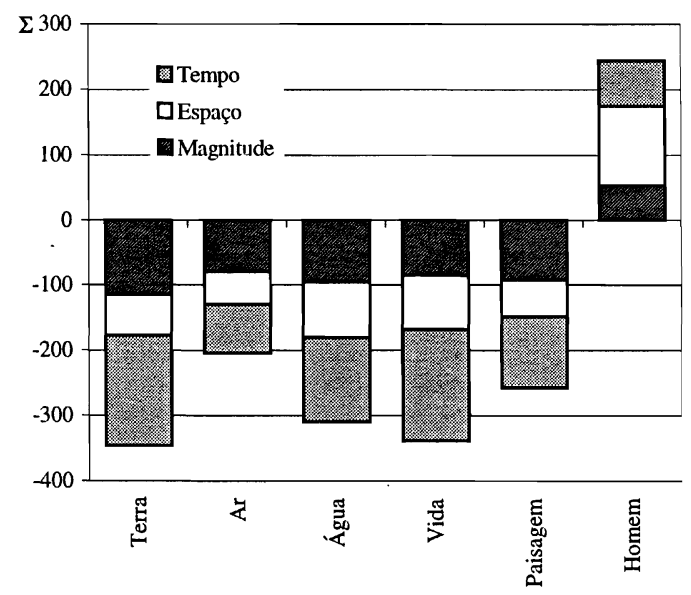

Fig. 5 - Valoração total dos impactes sobre cada um dos elementos ambientais

\section{CONCLUSÃO}

A elaboração das matrizes de interacção para análise de impactes ambientais no Baixo Mondego revelou-se uma experiência extremamente enriquecedora no que diz respeito à detecção e compreensão dos principais impactes ambientais verificados neste espaço, por força de um conjunto de acções de desenvolvimento que aqui têm vindo a ser aplicadas, e sobretudo por aquelas que têm vindo a ser ensaiadas nos últimos vinte e cinco anos na sequência das obras de regularização hidro-agrícola. Através de um processo moroso e complexo, muito dependente de um bom conhecimento do território, das actividades que nele se desenvolvem e das populações que nele e dele vivem, foi possível um conhecimento que se pretende holístico e integrado das condições ambientais do Baixo Mondego e das principais ameaças a que está sujeito.

As condições ambientais do Baixo Mondego neste virar de milénio não parecem ser particularmente más. No entanto, há algumas ameaças ao nível dos solos, da manutenção da biodiversidade e, mesmo, da qualidade da água. A paisagem e o ar parecem um pouco menos ameaçados.

A análise das matrizes de impactes ambientais revela, ainda, o peso significativo que as transformações verificadas no Campo, e nomeadamente as modificações das técnicas agrícolas, estão a ter no desequilíbrio dos restantes ecossistemas do Baixo Mondego. Registe-se que muitos destes impactes têm um carácter permanente e irreversível e um alcance espacial que em muito pode ultrapassar o espaço regional do Baixo Mondego.

De qualquer modo, os impactes mais fortemente negativos são os que se prendem com actividades ligadas à indústria extractiva e à indústria transformadora. Impactes também fortemente negativos são os que decorrem do conjunto de actividades ligadas à expansão urbana ${ }^{4}$. Pensamos que em grande parte, estes impactes decorrem do modo desordenado, quase selvagem, como se processam muitas das actividades extractivas e de indústria transformadora e o modo de apropriação dos solos para construção urbana, pelo que se torna necessária uma intervenção urgente das autarquias e, mesmo, do poder central, no sentido de proceder a um melhor ordenamento destas actividades, diminuindo os impactes negativos sobre o ambiente.

São as actividades tradicionais deste espaço aquelas que têm um balanço menos negativo nos impactes que geram (agricultura, mesmo modernizada, e a pesca, que chega a ter uma valoração de impactes ligeiramente positiva.

Registe-se, finalmente, que actividades como o turismo parecem poder desenvolver-se sem impactes negativos de monta nos elementos físicos do ambiente,

${ }^{4}$ De certo modo poder-se-á afirmar que grande parte dos incêndios florestais ocorridos neste espaço e particularmente na Serra da Boa Viagem não podem ser desligados desta problemática. 
podendo mesmo constituir-se como importantes suportes do desenvolvimento económico e de defesa do património natural e cultural.

\section{BIBLIOGRAFIA:}

AlmeidA, A. Campar (1995) - Dunas de Quiaios, Gândara e Serra da Boa Viagem. Uma abordagem ecológica da paisagem. Diss. Doutoramento, 305 p.

AlmeidA, A. Campar (1997) - "Apreciação da paisagem na Serra da Boa Viagem". Actas do III Congresso da Geografia Portuguesa, Porto (no prelo).

AlmeidA, A. Campar; SoARes, A. Ferreira; Cunha, Lúcio e Marques, Júlio F. (1990) - "Proémio ao estudo do Baixo Mondego". Biblos, Coimbra, LXVI, pp. 17-47.

Contreras, José Luis Sanz (1991) - "Concepto de impacto ambiental y su evaluacion". in Carcedo, Francisco Javier Ayala - Evaluacion y correccion de impactos ambientales. ITGE, Madrid, pp. 27-38.

CRISTO, F. Peixinho (1997) - "Águas subterrâneas no Baixo Mondego". Actas do Seminário O Baixo Mondego: organização geossistémica e recursos naturais. Coimbra, pp. 105-123.

CunHa, Lúcio (1997) - "Recursos turísticos no espaço do Baixo Mondego". Actas do Seminário O Baixo Mondego: organização geossistémica e recursos naturais. Coimbra, pp. 85-103.

CunHA, L. e JACINTO, R. (1995) - "A questão ambiental e a sua percepção em Portugal". Actas do VI Colóquio Ibérico de Geografia, Porto, 1992, pp. 1061-1074.

DAvid, J. e DuCRET, B. (1998) - "Environnement, répresentations et Géographie". Information Géographique. Paris, SEDES, $n^{\circ} 2$, pp. 85-91.

FeliX-FILho, José A. (1994) - "Aplicações de métodos de AIA em alguns casos reais". In PARTIDÁRIO, M. R. e Jesus, J. Avaliação do impacte ambiental. CEPGA, Lisboa, pp. $472-$ -513 .
Hespanha, Pedro e ReIS, José (1988) - O desenvolvimento do Baixo Mondego - economias regionais e intervenção do Estado. Coimbra, CCRC.

LAPA, M. L. R. e Mendes, D. A. P. (1997) - "Os recursos naturais não metálicos da região do Baixo Mondego". Actas do Seminário O Baixo Mondego: organização geossistémica e recursos naturais. Coimbra, pp. 61-83.

LEOPOLD et al. (1971) - "A procedure for evaluating environmental impact". US Geological Survey Circular, 645, Washington.

Martins, A. Fernandes (1949) - O esforço do Homem na Bacia do Mondego. Coimbra, 1949.

Mendes, H. P., Morais, A. e Lima, J. P. (1996) - "Impacte dos sistemas de rega e drenagem na agricultura do Baixo Mondego - Inquérito à população". Cadernos de Geografia, Coimbra, 15 , pp. $75-83$.

Monteiro, Ana (1998) - "Contribuição para o estudo das implicações no clima local gerados pela construção de uma barragem". Revista da Faculdade de Letras da Universidade do Porto - Geografia, Porto, IV, pp. 157-218.

Paiva, Jorge (1996) - Paúis do Baixo Mondego. Instituto da Conservação da Natureza.

Rebelo, Fernando, Cunha, Lúcio e Almeida, A. Campar (1990) - "Contribuição da Geografia Física para a inventariação das potencialidades turísticas do Baixo Mondego". Cadernos de Geografia, Coimbra, 9, pp. 3-34.

Ribeiro, Orlando (1987) - Portugal, o Mediterrâneo $e$ o Atlântico. $5^{\mathrm{a}}$ ed., Lisboa, Livraria Sá da Costa.

Silva, Carlos (1995) - Clima e orizicultura no Baixo Mondego. Diss. Mestrado, Coimbra, 149 p. + anexos.

SOARES, A. F. (1966) - "Estudo das formações pós-Jurássicas na região entre Sargento-Mor e Montemor o Velho (margem direita do Rio Mondego)". Rev. Fac. Ciências Univ. Coimbra, vol. XL, Coimbra.

Sociedade e Território - Revista de Estudos Urbanos e Regionais, Porto, n² 27, Junho de 1998. 